\title{
Acute necrotizing encephalopathy of childhood
}

INSERM

\section{Source}

INSERM. (1999). Orphanet: an online rare disease and orphan drug data base. Acute necrotizing encephalopathy of childhood. ORPHA:263524

Acute necrotizing encephalopathy of childhood is a rare neurologic disease characterized by a rapid onset of seizures, an altered state of consciousness, neurologic decline, and variable degrees of hepatic dysfunction following a respiratory or gastrointesitnal infection (e.g. mycoplasma, influenza virus) in a previously healthy child. Brain MRI of patients reveals bilateral, multiple, symmetrical lesions predominantly observed in thalami and brainstem, but also in periventricular white matter and cerebellum in some cases. 